\title{
Renal function after long-term treatment with lithium
}

\author{
R P HULLIN, V P COLEY, N J BIRCH, T H THOMAS, D B MORGAN
}

British Medical fournal, 1979, 1, 1457-1459

collect the urine had been given to each patient at the previous visit. Only 24-hour collections containing over $80 \%$ of the daily lithium dose were accepted as complete. If the collection contained less than this it was repeated once after further instructions and explanations. A total of 106 patients produced a satisfactory collection.

\section{Summary and conclusions}

Daily urine volumes, plasma creatinine concentrations, and creatinine clearance were measured in 106 patients with unipolar and bipolar affective disorders attending a "lithium" clinic. Urine volumes exceeded 3.51 in only six patients, plasma creatinine concentrations exceeded $150 \mu \mathrm{mol} / 1(1.7 \mathrm{mg} / 100 \mathrm{ml})$ in only five, and creatinine clearance was below $50 \mathrm{ml} / \mathrm{min}$ in 16 . Renal function was assessed by measuring creatinine clearance and renal tubular function, including response to 20 hours of water deprivation, in a representative sample of 30 patients from the lithium clinic and 30 psychiatric patients matched for age and sex who were taking other psychotropic drugs. Creatinine clearance and tubular function, including urine osmolality after water deprivation, were not significantly different between the two groups. Urinary excretion of arginine vasopressin (AVP), however, was much greater in the lithium-treated patients, who therefore had a diminished tubular responsiveness to AVP.

The findings do not support suggestions that long-term lithium treatment results in seriously impaired renal function, renal damage, and polyuria. Compared with other series, however, the patients were being maintained with low serum lithium concentrations, which apparently are as effective prophylactically as higher concentrations.

\section{Introduction}

Long-term treatment with lithium may cause polyuria ${ }^{1}$ associated with an increase in plasma antidiuretic hormone (ADH), ${ }^{2}$ and it is therefore due wholly or largely to diminished renal responsiveness to $\mathrm{ADH}$. The polyuria is troublesome but not serious. Recent reports, however, suggest that lithium reduces the glomerular filtration rate and causes a focal interstitial nephropathy ${ }^{3}$ Such reports cast doubt on the future use of lithium in the long-term treatment of recurrent affective disorders.

We have measured the daily urine volumes and creatinine clearance in 106 patients attending our "lithium" clinic. Thirty of these patients and 30 patients matched for age and sex who were taking other psychotropic drugs were admitted overnight and investigated for creatinine clearance and several renal tubular functions, including urine osmolality after water deprivation.

\section{Patients and methods}

Table I gives the details of 123 patients attending the clinic. All were asked to collect urine for 24 hours, ending at 0800 on the day of their next routine visit. Verbal and written instructions on how to

\section{University of Leeds}

R P HULLIN, PHD, FRIC, reader in biochemistry

V P COLEY, DPM, MRCPSYCH, clinical research fellow, departments of psychiatry and biochemistry

N J BIRCH, BSC, PHD, research fellow, department of biochemistry

T H THOMAS, BSC, PHD, biochemist, department of chemical pathology D B MORGAN, MD, professor of chemical pathology

TABLE I-Details of 123 patients attending lithium clinic

\begin{tabular}{|c|c|c|c|c|c|}
\hline & \multicolumn{2}{|c|}{ Age (years) } & \multirow{2}{*}{$\begin{array}{l}\text { Duration of } \\
\text { lithium } \\
\text { treatment } \\
\text { (months) }\end{array}$} & \multirow{2}{*}{$\begin{array}{l}\text { Serum } \\
\text { lithium } \\
\text { concentration } \\
12 \text { hours after } \\
\text { last dose } \\
(\mathrm{mmol} / \mathrm{l})\end{array}$} & \multirow{2}{*}{$\begin{array}{l}\text { Dosage of } \\
\text { lithium } \\
\text { carbonate } \\
\text { (mg) }\end{array}$} \\
\hline & $\begin{array}{c}\text { Men } \\
(\mathrm{n}=39)\end{array}$ & $\begin{array}{l}\text { Women } \\
(\mathrm{n}=84)\end{array}$ & & & \\
\hline $\begin{array}{l}\text { Mean }: S D \\
\text { Range }\end{array}$ & $\begin{array}{c}55 \cdot 6: 13 \cdot 7 \\
21-81\end{array}$ & $\begin{array}{c}54 \cdot 2-12 \cdot 9 \\
19-77\end{array}$ & $\begin{array}{c}74 \cdot 1+38 \cdot 8 \\
6-180\end{array}$ & $\begin{array}{c}0.59+0.17 \\
0.31-1.07\end{array}$ & $\begin{array}{c}802 \cdot 5+290 \cdot 0 \\
250-2000\end{array}$ \\
\hline
\end{tabular}

Conversion: SI to traditional units-Serum lithium: $1 \mathrm{mmol} / 1 \approx 0 \cdot 7 \mathrm{mg} / 100 \mathrm{ml}$.

We selected as a representative sample 30 patients who had been taking lithium for a mean of $8 \cdot 3 \pm \mathrm{SD} 2 \cdot 8$ years (range $3 \cdot 0-12 \cdot 4$ years) and 30 psychiatric patients matched for age and sex with the lithium group who were taking psychotropic drugs other than lithium. Patients and controls were admitted in random order to the research unit and stayed from 1800 till 1500 the next day. Subjects took no medication from 18 hours before admission until the end of the test except for $5 \mathrm{mg}$ nitrazepam on retiring to bed. Throughout their stay patients were supervised by the nursing staff of the unit, who ensured that they took no food or drink and that all urine was collected. The patients were accurately weighed at 1900, 0700, and 1500. Blood samples were taken, without stasis, at 0900 and 1400 into strontiumheparin tubes, which were stoppered so that no air was trapped above the blood. Urine was collected over 18 hours from 1900 to 1300 and used to measure creatinine clearance. A further, two-hour urine sample, collected between 1300 and 1500, was used to assess tubular function.

Plasma sodium, potassium, calcium, and bicarbonate concentrations and plasma and urine creatinine and phosphate concentrations were measured on a Vickers M300 multichannel analyser. Urine osmolality was measured on an advanced osmometer; urine $\beta_{2}$-microglobulin was measured by radioimmunoassay (Phadebas), and arginine vasopressin (AVP) was measured by a specific and sensitive radioimmunoassay. ${ }^{4}$ Urine AVP was expressed as osmolar clearance $(\mu \mathrm{g} / \mathrm{ml})$, which is closely related to plasma AVP.

Glomerular function-Creatinine clearance was calculated from creatinine excretion in the 18-hour urine collection and the creatinine concentration in the 0900 plasma sample.

Tubular function-Tubular reabsorption of small-molecular-weight proteins was assessed from the excretion of $\beta_{2}$-microglobulin in urine. The maximum tubular reabsorption capacity for phosphate per unit of glomerular filtration rate (GFR) was calculated from the phosphate and creatinine concentrations in plasma and urine. ${ }^{5}$ Tubular reabsorption of water was assessed from the 24 -hour urine volume in the large group and from the urine osmolality and weight loss after water deprivation for 20 hours in the smaller groups. In the smaller sample the relation between urine AVP and urine osmolality was used to assess tubular responsiveness to AVP.

\section{Results}

Only six of the 106 lithium-treated patients had a 24-hour urine volume exceeding $3.5 \mathrm{l}$, and only five had a plasma creatinine concentration above $150 \mu \mathrm{mol} / 1(1.7 \mathrm{mg} / 100 \mathrm{ml})$; two of these patients had both an increased urine volume and a raised plasma creatinine concentration. The 24-hour creatinine clearances were very variable (30 to $165 \mathrm{ml} / \mathrm{min}$; mean $75 \cdot 7 \pm \mathrm{SD} 30 \cdot 2 \mathrm{ml} / \mathrm{min}$ ). Thirty-eight patients had a creatinine clearance below $70 \mathrm{ml} / \mathrm{min}$, and in 16 it was below $50 \mathrm{ml} / \mathrm{min}$.

Table II shows the various assessments of renal function in the 
smaller, selected lithium group and controls. The two groups had similar mean plasma creatinine and creatinine clearance values. Many patients in each group had low creatinine clearance values; 16 controls and 18 lithium-treated patients had values below $70 \mathrm{ml} / \mathrm{min}$, and 10 of the controls and 13 patients in the lithium group had clearance values below $50 \mathrm{ml} / \mathrm{min}$. Except for two patients in the lithium group, however, the plasma creatinine concentration was normal in al patients.

TABLE II-Renal function in lithium-treated and control patients. Values are means $\pm S D$

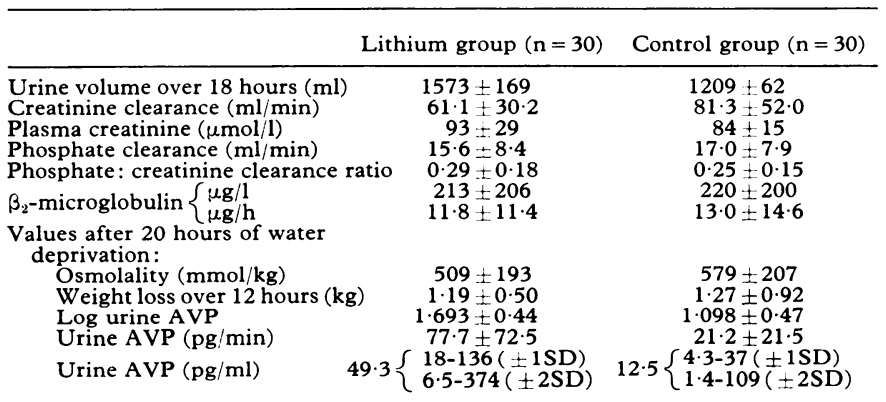

Conversion: SI to traditional units-Plasma creatinine: $1 \mu \mathrm{mol} / 1 \approx 0.01 \mathrm{mg} / 100 \mathrm{ml}$. Osmolality: $1 \mathrm{mmol} / \mathrm{kg}=1 \mathrm{mosmol} / \mathrm{kg}$.

Urinary excretion of $\beta_{2}$-microglobulin and tubular reabsorption of phosphate were similar in the two groups, as was the weight loss during water deprivation and the urine osmolality at the end of water deprivation. Urinary excretion of AVP, however, was much greater in the lithium-treated group.

Table III gives the plasma electrolyte, urea, and creatinine concentrations after water deprivation in the two groups. No significant differences were observed.

TABLE III-Mean plasma values $\pm S D$ after 20 hours of water deprivation in lithium-treated and control patients

\begin{tabular}{|c|c|c|}
\hline & Lithium group $(n=30)$ & Control group $(n=30)$ \\
\hline $\begin{array}{l}\text { Sodium }(\mathrm{mmol} / \mathrm{l}) \\
\text { Potassium }(\mathrm{mmol} / 1) \\
\text { Calcium }(\mathrm{mmol} / \mathrm{l}) \\
\text { Bicarbonate }(\mathrm{mmol} / \mathrm{l}) \\
\text { Urea }(\mathrm{mmol} / \mathrm{m}) \\
\text { Creatinine }(\mu \mathrm{mol} / \mathrm{l})\end{array}$ & $\begin{array}{rl}141.4 & 3.6 \\
4 \cdot 19 & 0.24 \\
2.65 & 0.16 \\
23.9 & 1.9 \\
4.97 & 1.17 \\
92.8 & 28.8\end{array}$ & $\begin{array}{c}140 \cdot 0: 3 \cdot 2 \\
4 \cdot 08=0.37 \\
2 \cdot 61: 0 \cdot 11 \\
26 \cdot 8-3 \cdot 3 \\
4 \cdot 71+1 \cdot 17 \\
83 \cdot 8=15 \cdot 3\end{array}$ \\
\hline
\end{tabular}

Conversion: SI to traditional units-Plasma sodium, potassium, and bicarbonate $\mathrm{mmol} / 1=1 \mathrm{mEq} / 1$. Plasma calcium: $1 \mathrm{mmol} / 1 \approx 4.0 \mathrm{mg} / 100 \mathrm{ml}$. Plasma urea: $1 \mathrm{mmol} / 1 \approx 6.0 \mathrm{mg} 100 \mathrm{ml}$. Plasma creatinine: $1 \mu \mathrm{mol} / 1 \approx 0.01 \mathrm{mg} / 100 \mathrm{ml}$.

\section{Discussion}

Of the 106 patients receiving long-term lithium treatment, only six had polyuria, and detailed study showed that as a group they could increase their urine osmolality as much as the controls during water deprivation. Urinary AVP in the lithium group, however, was higher for any urine osmolality than in the control group, which suggests diminished responsiveness and confirms the findings of Bayliss and Heath. ${ }^{6}$

There was no evidence of any deterioration in GFR due to lithium. Although the GFR as assessed by endogenous creatinine clearance was perhaps low on average compared with generally accepted standards, it was not lower in the lithium group than in a group matched for age and sex taking other psychotropic drugs. Hestbech $e t a l^{3}$ reported that patients receiving long-term lithium treatment have a reduced GFR and interstitial nephropathy. Hansen and Amdisen, ${ }^{7}$ who investigated 21 patients who had developed intoxication during maintenance treatment with lithium at a dosage that had been unchanged for months to years, reported that water loss due to impaired renal concentrating ability seemed to be a major predisposing factor for intoxication.
In seven patients renal biopsy showed abnormalities suggesting a chronic nephropathy, possibly caused by lithium, which might be another predisposing factor. Hestbech and Aurell ${ }^{8}$ reported a case of probable lithium-induced uraemia in a patient given regular lithium treatment for only three years; they also found that eight out of 110 patients treated with lithium for more than six months had signs of reduced renal function. Abnormal histological findings in the kidneys of lithium-treated patients were confirmed by Burrows et al, ${ }^{9}$ who also reported an additional unique tubular lesion in patients taking lithium. Other workers ${ }^{1011}$ found that long-term lithium treatment damages the kidney, but some of the patients examined had had previous episodes of lithium intoxication and many had severe polyuria.

Our failure to find a reduced GFR in the lithium group could be due to error in measuring GFR from creatinine clearance, use of an inappropriate control group, or a real difference between our lithium-treated patients and those investigated by others. Abnormal glomerular function is difficult to detect with creatinine clearance because of errors in urine collection and the large variability in normal clearances, particularly with age. Nevertheless, whereas the urine collections may have been incomplete in the outpatients despite the precautions taken, this is most unlikely to have been the case in the inpatients because of the personal supervision. In any event none of these problems would explain our failure to find a difference between the lithium and control groups. Our controls were taking psychotropic drugs other than lithium and might themselves have had diminished renal function. The use of such a control group, however, can be justified since the treatment for recurrent affective disorders is not lithium or nothing but antidepressant drugs with or without anti-manic drugs given symptomatically for each episode of affective illness. It may, indeed, be argued that it was not appropriate to choose donor kidneys not used for transplantation as the control specimens for histological studies.

There was, however, a major difference between our lithiumtreated patients and those investigated by others-namely, we used smaller and divided doses of lithium. In a study by Hestbech $e t a l^{3}$ five out of 14 patients had had previous episodes of lithium intoxication and the average 12-hour serum lithium concentration for the whole group was $0.94+\mathrm{SD} 0.09 \mathrm{mmol} / \mathrm{l}$ $(0.65 \pm \mathrm{SD} 0.06 \mathrm{mg} / 100 \mathrm{ml})$, which was much higher than the average concentration used by us $(0.59 \pm 0.17 \mathrm{mmol} / 1 ; 0.41 \pm$ $0.12 \mathrm{mg} / 100 \mathrm{ml}$ ). Our method of management was also associated with a lower incidence of polyuria and hypothyroidism. Only $6\left(5 \cdot 7^{\circ}\right)$ of our 106 patients had polyuria, whereas this occurs in over $30^{\circ}{ }_{0}$ of patients in other centres. Only $9\left(8.5^{\circ}{ }_{10}\right)$ of our patients had hypothyroidism, ${ }^{12}$ defined as a definite and persistent rise in thyrotrophic hormone, whereas this occurs in $\left.15-33^{\circ}{ }_{1}\right)^{13-15}$ of patients in other centres. Our doses were adequate for prophylaxis, however, as there was no increase in the frequency of clinical relapse in patients with unipolar or bipolar disorders treated with long-term lithium until the 12-hour plasma lithium concentration fell below $0.4 \mathrm{mmol} / 1(0.3 \mathrm{mg} /$ $100 \mathrm{ml}$ ), when the yearly frequency of relapse increased from $10-15^{\circ}$, of patients to over $50 \%{ }^{16}$

These findings support the suggestion that the lack of significant effects of lithium on renal function in our patients was due to our use of smaller but equally effective doses of lithium. Nevertheless, since it is common to continue lithium treatment for many years, if not indefinitely, and because the nephrotoxic effects of other drugs such as analgesics take decades to develop, longer observation will be necessary even at these smaller doses before lithium can be exonerated as an agent that might produce unwanted effects on the kidney.

We thank the nursing staff of the research unit and the technicians of the pathological laboratory at High Royds Hospital; the technicians of the department of chemical pathology, University of Leeds, for invaluable help; and Dr R McDonald, High Royds Hospital, for permission to study his patients. The work was supported by a Medical Research Council programme grant to RPH. 
Requests for reprints should be addressed to: $\operatorname{Dr} \mathbf{R} \mathbf{P}$ Hullin (Director), Regional Metabolic Research Unit, High Royds Hospital, Menston, Ilkley, Yorkshire LS29 6AQ.

\section{References}

1 Schou, M, Fournal of Psychiatric Research, 1968, 6, 67.

2 Padficld, P L, et al, British fournal of Psychiatry, 1977, 130, 144.

3 Hestbech, J, et al, Kidney International, 1977, 12, 205.

4 Thomas, T H, and Lee, M R, Clinical Science and Molecular Medicine, $1976,51,525$.

${ }^{5}$ Bijvoet, O L M, and Morgan, D B, in Phosphate et Métabolisme Phosphocalcique, ed D Hioco, p 153. Paris, L'Expansion Scientific Française, 1971.

6 Bayliss, P H, and Heath, D A, Annals of Internal Medicine, 1978, 88, 607.

7 Hansen, H E, and Amdisen, A, Quarterly fournal of Medicine, 1978, 186, 123.
8 Hestbech, J, and Aurell, M, Lancet, 1979, 1, 212.

- Burrows, G D, Davies, B, and Kincaid-Smith, P, Lancet, 1978, 1, 1310.

10 Rafaelsen, $\mathrm{O}$, in Proceedings of First International Lithium Congress, ed S Gershon, N S Kline, and M Schou. Amsterdam, Excerpta Medica, in press.

11 Schou, M, and Amdisen, A, in Proceedings of First International Lithium Congress, ed S Gershon, N S Kline, and M Schou. Amsterdam, Excerpta Medica, in press.

12 Hullin, R P, in Lithium in Medical Practice, ed F N Johnson and S Johnson, p 433. Lancaster, MTP Press Ltd, 1978.

13 Villeneuve, A, et al, Lancet, 1973, 2, 502.

14 Linstedt, G, et al, British fournal of Psychiatry, 1977, 130, 452.

15 Transbel, I, Christiansen, C, and Bastrup, P C, Acta Endocrinologica, 1978, 87, 759.

${ }^{16}$ Hullin, R P, in Proceedings of First International Lithium Congress, ed S Gershon, N S Kline, and M Schou. Amsterdam, Excerpta Medica, in press.

(Accepted 20 April 1979)

\section{SHORT REPORTS}

\section{Pyogenic meningitis due to a vertebral abscess}

Cervical vertebral abscess is a rare cause of meningitis. Diagnosis may be difficult as its symptoms and signs may be overshadowed by those of meningitis, as shown in the following case.

\section{Case report}

A 47-year-old man was admitted in September 1978 with a history of headaches for two weeks, deteriorating vision for five days, and nausea and vomiting for two days. Three months earlier he had fallen in the snow, hurting his left shoulder, and since then he had had constant pain in the left shoulder, radiating to the left side of his neck and to the occipital region. He had suffered from night sweats and had lost $13 \mathrm{~kg}$. His neck had been stiff for about two months. In June 1969 he had been treated for an extensive carcinoma of the pyriform fossa with radical cobalt radiation.

On examination he was obese, fully conscious and orientated, but aggressive and in pain. His temperature was $38.3^{\circ} \mathrm{C}$; he had appreciable neck stiffness, a positive Kernig's sign, bilateral papilloedema, and small pupils. There were no focal neurological signs. A computerised axial tomographic scan was normal. Lumbar puncture showed a cloudy cerebrospinal fluid which contained $1.71 \times 10^{9}$ white cells $/ 1$ ( $95 \%$ polymorphs and $5 \%$ lymphocytes); protein $1 \mathrm{~g} / 1$ and glucose $0.5 \mathrm{mmol} / 1(9 \mathrm{mg} / 100 \mathrm{ml})$. A Gram stain showed no organisms and culture was negative. Radiographs of his cervical spine showed only minor degenerative changes.

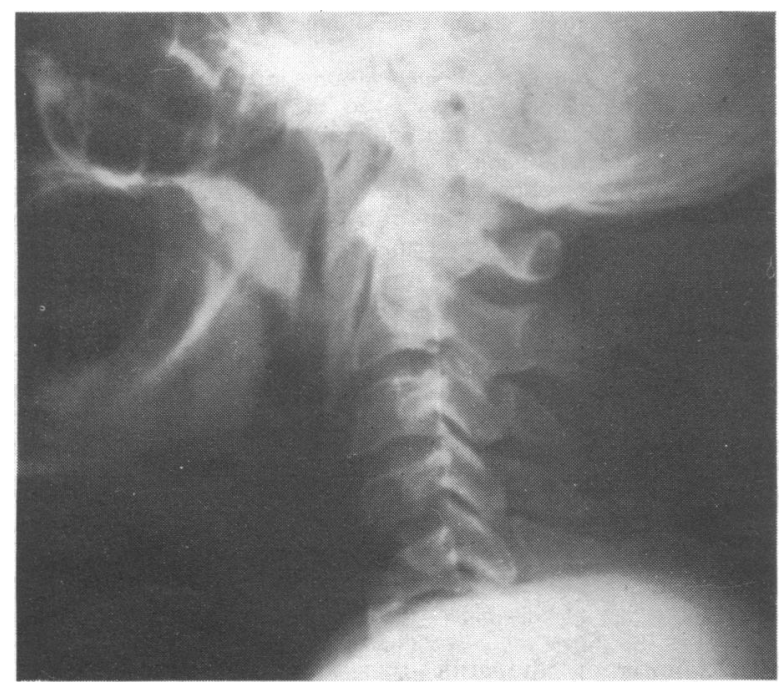

Radiograph of cervical spine showing erosion of anterior margins of fourth and fifth cervical vertebrae.
He was treated with analgesics and high doses of penicillin and sulphadiazine and dexamethasone. Although he improved symptomatically with the loss of his headache, he continued to have neck stiffness and he remained feverish after two weeks of chemotherapy. Radiography of his cervical spine with tomography now showed erosion of the anterior margins of the fourth and fifth cervical vertebrae adjacent to the disc, together with narrowing of the disc space and soft tissue swelling at this level (see figure). A technetium scan showed a high diffuse uptake throughout the cervical spine.

He then developed weakness of the right arm and signs of cord compression at C4-5 and his general condition deteriorated. An exploration of the neck was performed through an anterior approach, and necrotic material was aspirated from the disc space between $\mathrm{C} 4$ and $\mathrm{C} 5$. Bilateral ventricular drains were inserted. Bacteriological examination of the aspirate showed numerous neutrophils, Gram-positive cocci, and Gram-negative rods. Culture of both aspirate and ventricular cerebrospinal fluid showed a heavy growth of $\alpha$ haemolytic streptococci and Bacteroides melaninogenicus; both organisms were sensitive to penicillin. Fifty days after admission he died.

Necropsy showed evidence of a severe meningitis. The bodies of the fourth and fifth cervical vertebrae were collapsed and the centres were necrotic and infected. Pus communicated with the spinal canal through a hole in the posterior longitudinal spinal ligament which had been eroded at this level. Histological examination showed an acute purulent meningitis and the remains of an abscess within the fourth and fifth cervical vertebrae. There was no evidence of carcinoma affecting the cervical vertebrae.

\section{Comment}

The history of neck pain, night sweats, and weight loss, together with the presence of severe neck stiffness which was out of proportion to the other signs of meningitis, suggested the possibility of a cervical spine abscess. Normally a bone scan with technetium-99 is useful in diagnosing spinal osteomyelitis: in a series reported by Frederickson et al $^{1}$ a scan was positive in 12 out of 12 patients with spinal abscesses. But in our patient the diffuse isotope uptake in the cervical spine due to the presence of me.ringitis obscured the underlying abscess. Changes on radiographs of the spine occur late, and in this patient convincing evidence of an abscess was obtained only after tomography.

The organisms isolated from this patient's abscess and cerebrospinal fluid were unusual and were common throat commensals. They probably grew in an area of irradiation fibrosis in relationship to his previous treatment for carcinoma of the pyriform fossa. It is clearly important to aspirate and culture the pus. Failure of the patient's meningitis to respond to appropriate antibacterial treatment emphasises the importance of early surgical drainage when a spinal abscess is associated with meningitis.

${ }^{1}$ Frederickson, B, Yuan, H, and Olans, R, Clinical Orthopaedics and Related Research, 1978, 131, 160.

(Accepted 28 March 1979)

\section{Royal Infirmary, Sheffield}

CHRISTINE HOYLE, MBBS, house physician

W R TIMPERLEY, DM, MRCPATH, consultant neuropathologist J L MADDOCKS, MD, MRCP, consultant physician 